\title{
NAS ARMADILHAS DO DESEJO: privações e movimentos de jovens prostitutas em zonas rurais
}

\author{
Silvana de Souza Nascimento \\ Loreley Gomes Garcia**
}

\begin{abstract}
Este artigo busca problematizar os sentidos ambivalentes do lugar da prostituição feminina a partir de pesquisas realizadas com jovens mulheres no interior da Paraíba (região do Litoral Norte e Brejo Paraibano), provenientes de famílias rurais. As trajetórias de vida dessas mulheres revelam um histórico familiar marcado por vários tipos de violência e diferentes estratégias de autonomia para superar essas experiências de privação, embora, muitas vezes, elas se repitam na relação com os cafetões e com os clientes. A prostituição é vista como uma estratégia de empoderamento em relação ao próprio corpo, ao domínio de práticas sexuais pouco convencionais e, ao mesmo tempo, como uma situação de passagem, encarada como um meio para construir projetos futuros, ao menos idealmente, fora da prostituição. Nossa pesquisa, de caráter socioantropológico, revela que os mecanismos para a aquisição de autonomia reproduzem um modelo de dominação e oferecem poucas possibilidades para que essas jovens resistam às normatividades e moralidades vigentes.

Palavras-chave: Prostituição feminina. Juventude, Meio rural. Paraíba. Família.
\end{abstract}

\section{INTRODUÇÃO}

Pequenas cidades que margeiam estradas, federais e estaduais, no interior do Brasil possibilitam a oferta dos mais variados serviços para atender a uma clientela de caminhoneiros, trabalhadores rurais, operários de usinas, políticos, empresários etc. Uma cidade de beira de estrada, que aparentemente poderia ser pensada como um lugar pacato ou ermo, na verdade, pode revelar uma vida pulsante, especialmente para as mulheres que atendem a esses clientes afeitos por rápidas, nem sempre seguras, trocas sexuais. Lugares como esses são descritos pelos poderes públicos como fomentadores da exploração sexual infanto-juvenil, localizados na chamada "rota do sexo" pela Organização Internacional do Trabalho (OIT, 2007). São regiões de fácil circulação, situadas nas proximidades

\footnotetext{
* Universidade de São Paulo, Faculdade de Filosofia, Letras e Ciências Humanas, Departamento de Antropologia. Avenida Professor Luciano Gualberto. Butantã. Cep: 05508010. São Paulo - São Paulo - Brasil. silnasc@usp.br

** Universidade Federal da Paraíba, Centro de Ciências Humanas Letras e Artes, Departamento de Ciências Sociais.

Campus Universitário I. Castelo Branco. Cep: 58000000. João Pessoa - Paraíba - Brasil. loreleygg@gmail.com
}

de áreas metropolitanas de capitais e consideradas como uma periferia expandida, que invade as zonas rurais. A região do Brejo Paraibano, por exemplo, foi alvo, em 2007, de um inquérito deflagrado pela Procuradoria Regional do Trabalho da $13^{\mathrm{a}}$ Região, que culminou com a prisão de políticos locais e o fechamento de diversos espaços nos quais se realizavam formas de prostituição que envolviam adolescentes, de 12 a 17 anos. Essa região também foi o centro de uma reportagem na Folha de S. Paulo, em 2001, na qual se denunciava a existência de "leilões de meninas virgens".

Nesse árido cenário, constantemente vigiado e, ao mesmo tempo, volátil, realizamos, de 2011 a 2013, uma pesquisa socioantropológica em áreas rurais do interior do estado da Paraíba, com o intuito de mapear as formas de prostituição feminina e compreender como a atividade da prostituição perpassa tensões e conflitos em relação aos clientes, aos cafetões e cafetinas, à família, aos filhos e seus parceiros. ${ }^{1} \mathrm{O}$ objetivo foi compreender também em ${ }^{1}$ EDITAL MCT/CNPQ/SPM-PR/MDA n. 20/2010. Projeto de Pesquisa "Nas Armadilhas do Desejo". Equipe de pesquisa: Lorena Monteiro (mestranda em Sociologia, PPGS, UFPB Edilon Mendes Nunes (doutorando do PRODEMA, UFPB); 
que medida a prostituição se apresenta como um projeto para jovens mulheres, muitas delas abaixo dos dezoito anos, oriundas de regiões rurais e periféricas e observar de que modo elas vivenciam essa ocupação, por vezes considerada como um trabalho, outras como um momento de passagem para satisfazer às necessidades vitais imediatas, e outras ainda como uma estratégia de mobilidade social e rompimento do histórico de violência familiar.

A pesquisa foi realizada em duas regiões próximas à Região Metropolitana de João Pessoa: Mamanguape, localizada no Litoral Norte da Paraíba, município de produção canavieira e usinas de açúcar e álcool, e o Brejo, onde foram realizadas pesquisas nas cidades de Guarabira, Mari e Sapé, região de plantio de abacaxi, considerada um polo comercial regional. Ancoradas na metodologia feminista, buscamos compreender, de maneira ampla, as diferentes experiências, os significados e práticas do fenômeno da prostituição não metropolitana, cuja dinâmica escapa a um ambiente urbano propício a projetos individualistas de ascensão social.

A opção metodológica - a perspectiva etnográfica e o registro de histórias de vida buscou enfatizar a experiência pessoal e a vida cotidiana dessas mulheres para elaborar uma compreensão interpretativa da prostituição. A 늠 imersão nesse universo nos permitiu colocar, cados e as vivências nos seus múltiplos pontos de vista. Identificamos diversos espaços de : prostituição, desde residências até bares, boates e postos de gasolina e realizamos 40 entrevistas com mulheres jovens e adultas que entraram † na prostituição na adolescência. As moças e os $\therefore$ lugares tiveram suas identidades preservadas e

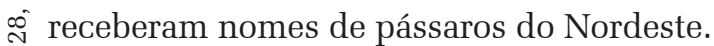

Apesar da diversidade das regióes observadas, apontamos recorrências nas trajetórias de vida das mulheres que se prostituem, o que inclui histórias de violência familiar e, por vezes, em Antropologia, UFRN); e Alberto Pessoa (professor de multimídia da UFPB e cartunista). violência sexual, e a iniciação, ainda na puberdade, nas atividades de prostituição. Os sonhos e as expectativas de projetos futuros limitam-se ao desejo de se tornarem empregadas domésticas ou donas de casa, casando-se com um "bom partido" que possa "tirar ela dessa vida". Encontramos mulheres que vieram de diferentes partes do país e que buscaram, na prostituição, estratégias de mobilidade social e sobrevivência econômica. A investigação revelou que as estratégias para a aquisição de independência ao mesmo tempo reproduzem um modelo de exploração e de dominação. Contudo, não propomos uma perspectiva redutora e vitimista (West, 2000), mas ensejamos pensar a prostituição como uma das poucas possibilidades que essas jovens possuem para obter autonomia e resistir às normatividades e moralidades vigentes.

McMullen (1987) analisa as causas da prostituição juvenil a partir da relação entre as necessidades emocionais e econômicas: “[...] um senso de poder pessoal mal desenvolvido e um sentimento profundo de ser irrelevante para alguém ou algo.” (McMullen, 1987, p. 39). Esse autor aponta a interconexão entre a falta de poder pessoal e a falta de poder econômico como agentes motivadores para a entrada das jovens na prostituição. Ambas as condições precisam estar presentes e aliadas para produzir essa escolha, pois apenas a pobreza não explica a opção das jovens pela prostituição.

Consideramos que a pobreza está acoplada a condições socioculturais que desvalorizam e desqualificam as jovens mulheres para que a prostituição se apresente como um projeto de mobilidade social e econômica. Além disso, ela possibilita a realização de desejos sexuais e afetivos pouco convencionais e a resistência ao modelo familiar tradicional.

\section{PROSTITUTAS NO MEIO RURAL: invisibilidade acadêmica \\ A produção das ciências humanas e so- ciais no país sobre prostituição tem crescido}


significativamente nos últimos anos, mas ainda há poucas pesquisas voltadas para o Nordeste e, em particular, para a prostituição rural. As pesquisas começaram a se desenvolver na década de 1980, acompanhando um fortalecimento dos movimentos sociais voltados para o comércio sexual. ${ }^{2}$ Segundo Fonseca (1996), a partir desse período, as pesquisas começam a desvendar a complexidade da prostituição e a buscar tentativas de classificação de suas práticas e protagonistas (Bacelar, 1982; Freitas, 1985; Gaspar, 1985; Perlongher, 1987). Esses trabalhos pretendiam quebrar com a imagem cristalizada da mulher prostituta como trans -histórica (advinda do feminismo radical nas décadas de 1960 e 1970) e como simplesmente vítima de um processo de exploração capitalista e patriarcal.

Perlongher (2008 [1987]), apesar de realizar um estudo sobre prostituição masculina (michês) em São Paulo, mostra-se como uma referência fundamental nesse conjunto de publicações, pois ele pensa a prostituição a partir da ideia de código-território. Esse autor identifica certo nomadismo guiado pelo desejo e, a partir de Deleuze e Guattari, observa que "o nômade estabelece localizações, mas não para de circular, de derivar" (Perlongher, 2008, p. 247). No caso de nossas pesquisas na Paraíba, o nomadismo evidencia-se desde a circulação entre municípios e cabarés, pontos e programas realizados na estrada, até relações afetivas que transitam entre homo e heterossexuais.

Da década de 1990 até hoje, pesquisas em grandes capitais realizaram uma aproximação entre a prostituição e organizações não governamentais que trabalham na prevenção de AIDS e de outras DSTs e na proteção dos direitos individuais e humanos das prostitutas (Fonseca, 1996; Olivar, 2007). Desde o último quarto do século 20, assiste-se à emergência de organizações integradas por prostitutas que reivindicam não só os direitos sociais de cidadania, mas também o reconhecimento da

${ }^{2}$ Em 1987, foi criada a Rede Brasileira de Prostitutas, com o intuito de buscar o reconhecimento da profissão. prostituição "como um trabalho como outro qualquer", o que acarreta direitos e deveres. É difícil estabelecer o limite do que é prostituição. Há um esforço para dissolver o estigma que marca as prostitutas e reforçar a proposta de legalização da atividade com o apoio das feministas, com ênfase na oposição entre os sexos. Isso é altamente controverso, pois, no feminismo de Beauvoir (1975), a prostituição aparece como "a expressão máxima da opressão feminina”. Entretanto, inúmeras feministas consideram que a legalização seria uma boa medida, pois minimizaria os perigos, livrando -as do jugo das organizações criminosas envolvidas no ofício. ${ }^{3}$

No campo das ciências sociais, é importante ressaltar que há pesquisadoras (es) que têm se debruçado sobre a relação entre prostituição, mercados transnacionais e turismo sexual. Piscitelli $(2005,2009)$ tem realizado uma pesquisa de referência no que se refere ao mercado internacional do sexo no Brasil, que é tratado, muitas vezes, como "turismo sexual”. Ela mostra que, em Fortaleza, muitas jovens meninas seduzem e se deixam seduzir pelos "gringos" como uma estratégia de ascensão social e possível viagem ou mudança para o exterior. Por outro lado, estrangeiros vêm à procura de sexo com brasileiras pelo fato de elas representarem, para eles, uma imagem da mulher tradicional, mais submissa, imagem que está em franco declínio nos países altamente industrializados. No caso das localidades pesquisadas na Paraíba, observamos que há movimentos transnacionais, especialmente em relação a travestis e transexuais, que não ${ }^{3}$ No Brasil, as políticas públicas voltadas à prostituição começaram a mudar na década de 1990, período no qual se incorporam ao debate novos elementos, perspectivas e sujeitos, além dos direitos das profissionais do sexo (Alvarez; Teixeira Rodrigues, 2001). Em 2002, a categoria foi incluída na Classificação Brasileira de Ocupações (CBO), apesar de não ter a profissão regulamentada. O título da ocupação é profissional do sexo e seus sinônimos: garota (o) de programa, meretriz, messalina, michê, mulher da vida, prostituta, trabalhador(a) do sexo. Os movimentos sociais da categoria têm atuado no sentido de apresentar uma política inclusiva para o trabalho sexual e da concretizaçã̃o de direitos para as profissionais do sexo. Dentro deste campo de atuação encontra-se a ONG Da Vida, fundada em 2002, e coordenada por Gabriela Leite, que é uma das principais lideranças da Rede Brasileira de Prostitutas. 
foram o alvo de nossa atenção, sendo que as mulheres têm apresentado, até o momento, trânsitos dentro do país, percorrendo capitais e cidades do interior, evidenciando que o circuito da prostituição não está limitado a grandes centros urbanos.

Com exceção de poucas pesquisas, tem-se como pressuposto de que as grandes cidades constituem locais propícios ao individualismo, onde diferentes formas de prostituição têm lugar, pois as normas que regulam as relações de gênero supostamente são mais flexíveis. Nota-se uma relação imediatista entre urbanização e prostituição, como se o meio rural fosse um paraíso para as "boas famílias", seio de uma tradição e de uma moralidade que não abre espaço para práticas sexuais cuja finalidade sejam as trocas econômicas e comerciais. Nesse modelo, o universo do campo estaria à margem das mudanças sociais, especialmente no que se refere à desestabilização dos lugares de gênero e do sexo não convencional.

Desse modo, o modelo teórico vigente associa-se às teorias clássicas de Simmel (2005), que sugerem uma intensificação da "vida nervosa" na metrópole, propiciando tipos de individualidade, fugacidade nas relações, intensa mobilidade e diversidade econômica, social e profissional. Sendo a metrópole 농 o local da economia monetária por excelência, : onde o dinheiro é a medida de todas as relações, seguindo o pensamento de Simmel, a metrópole também seria o lugar mais propício para a prostituição, pois ela envolve trocas sexuais por dinheiro. prostituição juvenil. Para compreender como esse fenômeno ocorre fora das grandes cidades, é preciso olhar para a condição de vida das mulheres na zona rural e suas implicações em termos de oportunidades e possíveis roteiros de gênero.
No modelo de família rural, as mulheres vivem uma situação de franca desvantagem, inseridas numa cultura que divide papéis, atribuições e valores de modo rígido e hierárquico, sob o controle do chefe da família (Portella; Silva, 2006, p. 132). Dessa forma, elas são privadas do acesso a direitos fundamentais e permanecem "tuteladas" pela família ou pelos companheiros (Garcia; Nascimento, 2013). Esse cenário, altamente desfavorável a transformações nas práticas e nas visões de mundo, abre as portas para a migração na busca de empregos e alimenta também o mercado sexual, que seduz com a promessa de um estilo de vida diferente. Assim, a prostituição, para jovens mulheres no campo, pode possibilitar a realização de desejos sexuais e afetivos pouco convencionais que, além de sugerirem a construção de projetos de mobilidade social, resistem ao modelo de família rural, onde necessariamente "lugar de mulher é na cozinha" (Nascimento, 2012).

\section{MAMANGUAPE: sexo on the road}

Saindo da capital João Pessoa, pela rodovia BR 101, em direção ao litoral norte, na divisa com o Rio Grande do Norte, encontramos uma antiga cidade, recortada ao meio pela estrada, que foi um dos poucos polos econômicos e políticos do Estado até o século 19. Atualmente, é uma das regiões mais pobres da Paraíba, com alta taxa de analfabetismo, mais de $50 \%$ da população considerada sem renda pelo IBGE e baixa expectativa de vida (média de 58 anos). ${ }^{4}$ Com cerca de 42.300 habitantes (Censo 2010, IBGE), Mamanguape apresenta-

${ }^{4}$ Mamanguape apresenta um dos piores indicadores sociais da Paraíba: expectativa de vida na ordem de 58,7 anos, taxa de mortalidade infantil de 67,4 por 1.000 crianças nascidas e até um ano de idade e a taxa de analfabetismo da população de mais de 15 anos de 46,0\%. Em 2003, apresentava um PIB na ordem de R\$ 492.656 mil, representando apenas $3,6 \%$ do PIB paraibano (IBGE). Pelo Censo 2000, Mamanguape apresentava 50\% de seus habitantes sem nenhuma renda. A alta taxa de analfabetismo de pessoas com 15 anos ou mais, segundo o Índice de Desenvolvimento de Educação Básica/Instituto Nacional de Estudos e Pesquisas Educacionais Anísio Teixeira (IDEB/ INEP), em 2005, era 38,3\% em Mamanguape. 
-se hoje com uma ocupação desordenada, monumentos históricos deteriorados, oferecendo trabalhos temporários nas usinas de cana (açúcar e álcool) e trabalhos informais no comércio, além de ser, particularmente, um lugar de passagem que se encontra entre duas capitais. Sua localização permite a articulação de redes de prostituição e uma constante mobilidade e migração de moradores de outras localidades, que ocupam a cidade seja para fugir da seca em municípios vizinhos, como Cuité de Mamanguape, seja para se encontrar parentes.

Nessa localidade, identificamos ao menos oito espaços de prostituição: residências das próprias mulheres que se prostituem, bares que oferecem quartos para os clientes, motéis espalhados ao longo da rodovia, postos de gasolina desativados, onde os programas acontecem dentro de automóveis e caminhões, casas em ruínas ocupadas por mulheres como lugar de moradia e trabalho, além de terrenos baldios, entre outros.

Os bares e o comércio do sexo são marcados por intensa rotatividade: abrem e fecham constantemente e mudam, com frequência, suas trabalhadoras, para que os clientes possam encontrar "novidades" desejáveis. O movimento da clientela também depende do período da moenda nas usinas de cana-de-açúcar. Nos tempos de maior movimento, os bares se enchem de clientes e mulheres à procura de clientes. Esses lugares constituem regiões morais (Parker, 2009), resultantes de restrições e permissões da vida social, que facultam a construção de códigos específicos para certos espaços, demonstrando uma divergência em relação às moralidades hegemônicas vigentes. "Uma região em que as pessoas que a habitam são dominadas, de uma maneira que as pessoas normalmente não o são, por um gosto, uma paixão, ou por algum interesse que tem suas raízes diretamente na natureza original do indivíduo.” (Parker, 2009, p. 72).

As "regiões morais" observadas, onde ocorrem práticas de prostituição, podem ser pensadas também como lugares intersticiais e de passagem, periféricos, pouco visíveis: beiras de estrada, saídas ou entradas de cidades, postos de gasolina, margens de rios e pontes, caminhos embrenhados, campos desocupados, casas em ruínas. Nas regiões morais, combinam-se diversas atividades ilegais ou estigmatizadas, como o tráfico de drogas, a prostituição, pequenos furtos e outras contravenções.

O primeiro contato com as mulheres que se prostituem foi no bar Arrocho: um espaço todo deteriorado, com quartos em ruínas, muito lixo, sem água nem iluminação. As moças cozinhavam em fogueiras improvisadas, com tijolos, panelas e latões, descansavam em colchões velhos e sujos, onde também recebiam clientes. À tarde, dormiam nas calçadas, sob uma árvore, aguardando o cair da tarde, quando começava a movimentação de caminhoneiros. "Quenga não dorme, cochila”, explica uma das mulheres do Arrocho. É preciso, de certo modo, sempre estar disposta a receber alguém e a ganhar algum dinheiro.

Apesar da proximidade de dois postos do Programa Saúde da Família (PSF) do bar Arrocho, observamos certa tensão entre os agentes de saúde, enfermeiras e as prostitutas atendidas. A procura pelos postos de saúde acontecia somente em casos extremos, e elas não costumavam realizar, com certa periodicidade, os exames de prevenção, muito menos recebiam preservativos. Assim, diversas vezes, encontrávamos jovens mulheres grávidas, nos espaços de prostituição, que, pelo menos à primeira vista, não se interessavam em realizar o pré-natal e entravam em conflito com as enfermeiras, que tentavam convencê-las em vão. Muitas grávidas continuavam realizando serviços de prostituição e planejavam a doação de seus filhos para pessoas da vizinhança, ou ainda a passagem da guarda para os pais biológicos. Das dez entrevistadas dessa região, metade delas relatou não ter coragem para fazer um aborto, devido a princípios religiosos. Das que já abortaram, 20\% sofreram abortos espontâneos. Uma entrevistada, durante os trabalhos de campo, estava grávida de cinco 
meses e continuava frequentando o bar, seu local de trabalho, mas não conseguia fazer programas. Segundo ela, os homens não a desejavam e contou, inclusive, que seu namorado, que também tinha outra mulher grávida, no mesmo período de gestação, já tinha tentado provocar um aborto agredindo-a com uma facada em sua barriga.

A doação dos filhos não pareceu ser um sofrimento ou conflito em relação à maternidade, mas uma estratégia para manter a autonomia, poder circular livremente pelos espaços de prostituição e mudar-se quando desejar. A mobilidade, para elas, parecia ser incompatível com a criação dos filhos. Entretanto, havia contradições em relação à maternidade, pois grande parte das mulheres grávidas que encontramos conheciam os pais de seus filhos e pareciam manter algum laço afetivo com eles. Isso demonstra que elas discriminavam com quem usavam preservativos e abandonavam o uso quando estavam em uma relação estável, ou com um "cliente fixo", muitas vezes também chamado de "namorado".

Diferentemente do Arrocho, o bar Caruê tinha certa configuração "familiar" e dividia espaço com a residência do proprietário, sua esposa e duas filhas. A relação entre as moças e o proprietário mantinha uma aparência quase $\stackrel{20}{5}$ paternal, e ele não aceitava o uso de qualquer $\stackrel{\sim}{\circ}$ droga ilícita em seu estabelecimento. Quando não conseguiam programas e estavam sem dinheiro, ele oferecia alimentação e sua esposa cuidava dos filhos para que elas fizessem programas. Era comum ver crianças circulando dentro do bar e suas imediações. Observamos * também outros bares, como o de Dona Choca, a com a presença maior de meninas e mulheres

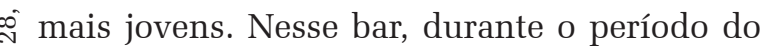

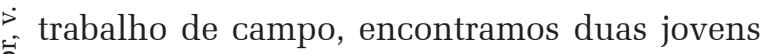
originárias do Rio Grande do Norte, que estavam "sob tutela" da dona bar, já que, segundo ela, as avós tinham deixado as meninas sob seus cuidados e, portanto, só podiam sair dali com sua autorização ou com um pagamento realizado por algum cliente que desejasse pas- sear com elas. Para saírem do bar e fazerem um programa, o cliente precisava pagar "a saída" para a proprietária, além do programa em si. Esse lugar era bastante frequentado por trabalhadores das usinas e havia toda uma programação que acompanhava os pagamentos quinzenais, e os períodos da moenda.

O preço do programa varia de acordo com o lugar, o bar e a mulher. Foram citados os valores de $R \$ 10,00$, R $\$ 20,00$ ou $R \$ 40,00$, $\mathrm{R} \$ 60,00$ reais. Se o cliente for turista ou quiser passar a noite, o preço é maior. Quanto ao tipo de programa, afirmaram que se resume ao trivial. Alguns bares acolhem meninas usuárias de drogas, especialmente o crack, outros proíbem qualquer uso de drogas ilícitas. Quando o uso é tolerado, observamos que o fornecimento das substâncias pode ser feito pelo próprio proprietário do lugar, que retroalimenta o vício e um modo de vida precário das mulheres. Quando elas estão na "noia", ${ }^{5}$ fazem programas a preços mínimos ( $R \$ 5,00$ a $R \$ 10,00)$.

Há uma grande mobilidade dessas mulheres entre cidades, e dentro da própria cidade. O tempo de vivência nos lugares por onde passam pode ser bem curto, só o suficiente para conhecer algumas pessoas ou trabalhar. Umas passam dias, outras passam meses ou anos. O modo como chegam a esses lugares é através de carona na estrada. Chegam ao Rio de Janeiro, a Maceió e a Fortaleza dessa forma. Também podem chegar por meio de amigas e conhecidas, que circulam dentro de um circuito de prostituição regional.

Há também uma alternância entre estar ou não na "vida no brega" (prostituição), o que depende de estarem casadas ou morando com o companheiro. Nesse caso, elas param de fazer programas ou o fazem sem o consentimento do parceiro. Contudo, quando há a separação, o que acontece de forma frequente, retomam os programas de forma mais livre. "Ser de todo mundo" não significa "não ser de ninguém". A grande maioria afirma ter um parceiro atualmente.

${ }^{5}$ O estado de "noia” refere-se a períodos de abstinência em relação ao uso do crack. 
Suas primeiras experiências sexuais coincidem, na maioria dos casos, com a idade em que entram na puberdade. Mas pode acontecer antes. Uma das entrevistadas relatou ter sido estuprada aos nove anos, violada a caminho da escola por um amigo da família. Não foi a única iniciada na sexualidade com violência e antes de entrar na puberdade.

Todas têm família, costumam ir às suas cidades visitar os parentes e filhos no dia de folga. Outras já não têm quem visitar. Cada uma definiu seu conceito de família. Possuem pai e mãe, juntos ou separados, apenas avó, apenas mães, ou são órfãs de mãe e pai. Muitas não sabem qual a expectativa das famílias sobre elas, mas outras sabem que as famílias não queriam que fossem o que são.

Eu acho que foi mais por causa da minha família, revoltada principalmente com minha mãe. Só me chamava de rapariga, aí eu me arretei (Mãe da Lua).

Perguntamos se, caso tivessem nascido meninos, sua vida seria diferente. Elas afirmam que sim, pois os homens têm mais liberdade e, se tivessem nascido homens, estariam casados, com seus filhos e suas esposas em casa. Assim, os planos e sonhos para o futuro incluem casar, ter o próprio negócio, uma casa própria, trabalhar em casa de família, se aposentar, voltar para a igreja etc. Um conformismo se sobrepõe ao desejo de mudança, ainda que a ampla maioria tenha dito que pretende sair da prostituição.

A dinâmica da vida e a trajetória das protagonistas têm implicações diretas no nível de escolaridade e vice-versa. Os estudos não representam prioridade para nenhuma das entrevistadas. Das que responderam às perguntas relativas à escolaridade, $70 \%$ das entrevistadas, $40 \%$ delas cursou entre a $1^{\mathrm{a}}$ e a $4^{\mathrm{a}}$ série; $20 \%$ entre a $5^{\mathrm{a}}$ e $8^{\mathrm{a}}$ séries; e apenas $10 \%$ cursou o Ensino Médio. Existem casos em que elas se recusam a ir à escola porque não conseguem aprender nada. Entre as causas de interrupção dos estudos estão: falta de motivação, problemas familiares, casamento, filhos em idade precoce. Também as drogas interferem na vida escolar, pois algumas abandonam os estudos para se prostituir e custear as drogas.

É comum, entre as mulheres, deixar os estudos quando assumem todas as tarefas domésticas depois do casamento. Cabe ressaltar que muitas se casam ainda adolescentes. Juruva, por exemplo, "casou" aos 10 anos, trabalhou em casa de família, mas prefere a vida no bar onde faz programas desde 12 anos. Mesmo com pouca escolaridade, elas possuem experiências de vida, destreza nas negociações e muito tino para despertar o desejo alheio.

\section{CENÁRIOS BREJEIROS: sexo privê (Guarabira, Mari e Sapé)}

Na região do Brejo Paraibano, as pesquisas foram vistas com desconfiança por parte das interlocutoras, devido a uma ação civil do Ministério Público do Trabalho, conforme foi mencionado na introdução. Muitos locais de prostituição foram desativados. Contudo, pela própria mobilidade da atividade, outros espaços foram abertos e as atividades continuam cotidianamente.

Realizamos entrevistas em três municípios: Guarabira, Mari e Sapé. Todos são lugares pouco industrializados, marcados pela vida rural, onde predomina a agricultura. As cidades de Guarabira e Sapé são de porte médio, com cerca de 50.000 habitantes e bastante movimento comercial; já Mari tem pouco mais de 20.000 habitantes e pouco comércio.

Nossa amostra correspondeu a cinco locais, com ambientes bastante diferenciados e especificidades quanto ao movimento, funcionamento, clientela e prostitutas. Por exemplo, o Bar do Japim fica numa avenida principal da periferia de Guarabira que conecta a cidade com a BR 230, em frente ao Motel "Você que sabe". Nesse bar, a esposa e a nora do dono trabalham na cozinha, ele e as moças trabalham no salão onde duas crianças, entre elas o neto do dono do bar, presenciavam todas as cenas até a noite: 
mulheres sentando no colo dos homens, dançando; esfrega-esfrega; os homens passando as mãos nas pernas e nas bundas das mulheres; cheiros, beijos etc. Os frequentadores têm idade e perfil variados. A maioria dos "garçons" e das "garçonetes" também prestava serviços sexuais. Mas, segundo o dono, esses serviços não aconteciam nos espaços do bar, mas nos motéis.

$\mathrm{Na}$ aproximação entre cliente e prostituta, geralmente, a iniciativa partia do cliente que chamava a garçonete para sua mesa ou passava a mão nas pernas enquanto circulavam. As moças dançavam de forma sensual no salão do bar ou na frente dos clientes, que, muitas vezes, aproveitavam a oportunidade para tocar nos seios das "bailarinas”. Às vezes, elas recusavam clientes, que reagiam com insistência, mas terminavam desistindo, decepcionados ou reclamando, sem esboçar violência. A interação entre moças e clientes parecia ser impessoal: um leve sorriso durante uma conversa com os clientes desaparecia quando se viravam de costas.

A Pousada João-de-Barro, por sua vez, situava-se ao lado da grande feira livre de Guarabira, que atrai comerciantes e clientes da região. Havia quinze quartos e dois banheiros. $\mathrm{O}$ bar, do lado de baixo da pousada, atraía clientes de todas as idades, desde adolescentes até se$\stackrel{10}{7}$ nhores de oitenta anos, senhores vestidos com - camisa e calça social, comerciantes da feira, trabalhadores rurais, e jovens vestidos ao estilo rap. Entre os homens, circulavam várias mulheres entre 20 e 50 anos conversando e bebendo com eles. Elas serviam as mesas e ajudavam no bar, enquanto esperavam ser chamadas para

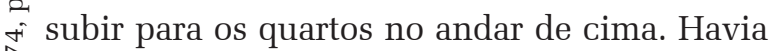
\& um desequilíbrio entre o número de homens e

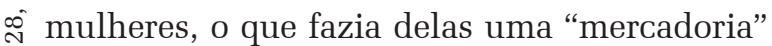
$\vec{i}$ escassa, disputada por homens que esperavam "sua vez". Tudo é pago separadamente, para o dono do bar: R \$ 10,00 pelo quarto e as bebidas, para elas os R\$30,00 pelo programa. ${ }^{6}$

${ }^{6}$ Nesse local, as entrevistas foram realizadas nos quartos por pesquisadores do sexo masculino e pagamos o equivalente ao programa.
Em Mari, identificamos um ponto de prostituição: o Bar das Tiribas, localizado no Motel Tapema, ao lado da pista principal. Geralmente, as mulheres só passavam uma temporada no local, permanecendo um final de semana ou um feriado para atender a clientes. Durante o período em que permanecem no bar, estão disponíveis em qualquer horário do dia. A gerente, Jacu, é ex-prostituta e mulher do proprietário do bar. Jacu já foi presidiária por tentativa de homicídio. Segundo seu relato, ela tinha uma relação afetiva com uma menina de doze anos e, num certo momento, descobriu que seu companheiro, na época, também se relacionava com ela. Quando soube da relação triangular, deu três facadas na menina e foi presa.

Em Sapé, a prática da prostituição era completamente distinta. Havia dois bordéis, o Sanhaço Bar e o Sapucaias Bar, do mesmo proprietário e que estavam localizados na entrada e na saída da cidade, pontos de grande circulação de veículos, mas fora dos centros urbanos. Os estabelecimentos ocupavam vastas casas de um andar, com um salão grande e fechado para a rua, banheiros e quartos no fundo. As moças alternavam os trabalhos entre um e outro bar, inclusive como forma de reciclagem dos serviços sexuais e de oferecer "carne nova" para os clientes. Da tarde até a madrugada, seguranças fardados e armados permaneciam nas entradas. Era proibida a entrada de mulheres.

Nesses locais, diferentemente de todos os outros, no Brejo e no Litoral Norte, as jovens mulheres estavam mais arrumadas, usavam "trajes típicos" da profissão: saias curtas, blusinhas com brilho, maquiagem, cabelos bem penteados e sandálias de salto alto. Atuavam de forma bem mais ativa que nos outros bares e também faziam performances de strip tease e pole dance. Ao entrar, o cliente era atendido pelas moças, que ofereciam bebida e companhia, encostando e tocando os clientes. Elas devem fazer com que eles gastem o máximo possível no bar. Caso o cliente não tomasse a iniciativa de convidá-las para o "programa", elas começavam a dançar, tiravam peças de roupa, provocando-o. 
Os preços e formas de pagamento eram regulamentados: $\mathrm{R} \$ 50,00$ para 30 minutos de sexo vaginal e oral, mais $\mathrm{R} \$ 10,00$ pelo quarto a ser pago antecipadamente no balcão do bar. Sexo anal custa R\$ 80,00, se for oferecido pela moça. As moças recebiam o dinheiro depois de descontadas as despesas do estabelecimento. No bordel, elas vivem sob constante vigilância do dono e seus funcionários: não podem sair com outros homens e, geralmente, trabalham todo o tempo. Durante nossas visitas, encontramos corpos com sinais de violência: nos rostos, nos braços e nas pernas. Segundo elas, os hematomas eram resultado de um acidente,/ queda ou de briga entre elas, porém não foi possível saber a origem verdadeira das marcas.

$\mathrm{Na}$ região do Brejo, a maioria das entrevistadas tem filhos: uns vivem na casa dos pais, outras crescem em colégio interno, outros são criados por parentes. Algumas casaram aos 13 ou 14 anos, grávidas, ou engravidaram na primeira relação sexual com o namorado. Há as que deram algum filho e há as que se recusam a fazê-lo. As famílias são bastante heterogêneas; o padrão heterossexual prevalece, mas há gays, lésbicas ou um pai homossexual. Há irmãs se prostituindo.

A maioria das famílias não sabe que elas são prostitutas. Algumas sabem e aceitam. Em alguns casos, até os próprios maridos, exigem que elas façam programa bem longe da cidade onde moram. Há mulheres casadas, separadas, as que entraram "na vida" por conselho das amigas, de parentes e até da sogra; ou fazem programa como a mãe fazia no passado.

Sobre o aborto, há muito tabu. Apenas $10 \%$ afirmaram ser favoráveis ao aborto; entre as que praticaram, há muita culpa. Outras não provocaram, mas alguma situação violenta, como surras, raiva e desgosto, ou um grande susto foram motivos para abortar.

Entre as moças, há quem optou pela prostituição e se sente satisfeita nessa profissão. Mas há as que não gostam do que fazem:

Queria que eu fosse totalmente diferente. É a parte de mim que eu odeio. Uma é a sociedade que fica me discriminando. A segunda é que eu fico sem moral [...] Não posso ter moral que eles vão dizer assim: “Quem é você pra você dizer isso de mim?” E a terceira porque eu sinto nojo de mim mesma. Fazendo uma coisa que eu vejo que eu sou totalmente errada [...]. Eu me sinto com uma culpa pesada, enorme. Cada vez que eu deito aqui, eu me sinto com um peso na consciência, me sinto culpada. (Caracará)

A maioria frequentou a escola entre a $1^{\mathrm{a}}$ e $4^{\mathrm{a}}$ série e, atualmente, apenas uma ainda estuda na Educação de Jovens e Adultos. Elas frequentaram a escola com idade acima da média adequada para a série que cursavam. Uma única universitária é graduada em Geografia e chegou a cursar Ciências Contábeis. Entre os motivos para o abandono da escola está a falta de interesse, mas o motivo recorrente para a evasão é o casamento e a gravidez precoce.

As primeiras experiências das entrevistadas com sexo ocorreram quando elas tinham entre 9 e 17 anos, sendo que duas meninas se iniciaram na vida sexual antes da primeira menstruação.

Eu não conseguia falar porque eu pensei que [...] não iam acreditar em mim, iam me chamar de mentirosa e eu podia até apanhar ou então ele pegar ainda mais pesado comigo... Escondido. Eu pensava que iam achar que era culpa minha por causa das roupas que eu vestia, eu gostava de roupas pequenas. E não foi uma vez só. Foram várias vezes que eu fui abusada sexualmente (Curió).

Quando perguntamos se pretendem continuar "na vida", nem 10\% admitiram que pretendem. A maioria manifesta desejo de sair. Desde que não pretendiam continuar na prostituição, perguntamos também o que precisavam para sair, e suas respostas mostraram o desejo de constituir uma família e conseguir um emprego. Outras disseram que ficarão até conseguir terminar a construção de uma casa própria, ou juntar dinheiro para realizar outros projetos, como terminar os estudos, abrir o próprio bar e, claro, casar "vestida de noiva" com "um bom homem".

Frequentemente, encontramos mulheres que apanharam do companheiro, em casa ou foram violentadas. 
Uma vez quando eu tinha assim uns 9 anos, meu irmão, o que eu não falo com ele, eu detesto ele, tentou me cutucar! Aí eu contei a mãe e não acreditou porque ele é filho biológico dela e eu não sou. Eu acho que ela pensou que eu tinha criado a história. Mas até hoje eu me lembro disso (Águia).

Na profissão, Tauató foi estuprada por um cliente e foi levada ao hospital. Além de clientes, os próprios maridos ou parceiros querem tomar as mulheres à força, violentando-as e cometendo crimes bárbaros.

Eles me amarraram em cima da cama, uma daquelas cama de madeira. Me amarraram, e aí o sangue... Eles me deixaram amarrada e saíram do quarto e continuaram bebendo no salão. Aí o dono do bar desceu, ele sentiu, vou ver como que tá ela. Quando chegou e me viu ele endoidou a cabeça. Me pegou no braço, enrolou na toalha, o sangue já tava enorme em cima da cama. Eu não sei como não morri. Me levou pro hospital, aí voltou e matou os dois (Tauató).

No entanto, algumas delas não são completamente passivas em situações de violência.

Já aconteceu comigo quando eu trabalhava na pista. Em Cabo Branco, o cara me levou pra Jacarapé e tomou meu dinheiro todinho. Eu lutei com ele porque queria enfiar dois vasilhames de cerveja na minha vagina e me apagar; olha foi um terror, foi por isso que eu deixei de ir pro Cabo Branco. Eu passei 3 anos aí larguei. Levei duas investidas a primeira vez o cara me comeu e me deixou lá e, na segunda, já no final de tarde, ele disse que ia me levar pra pousada Bandeirantes no Muçumago, quando chegou na entrada do Jacarapé ele entrou pra dentro do mato; eu ia pular mas ele falou que estava armado e, quando chegou lá, começou a luta, ele tentando enfiar o casco, a parte fina ainda dava pra entrar, mas a parte grossa não tinha quem fizesse entrar de jeito nenhum. Aí eu me agarrei nele e comecei a lutar, peguei nos ovos dele, lembrei que a força dos homens tá nos ovos e dei um chute nos ovos dele; aí ele se afastou aí eu quebrei o para brisa dele atrás e joguei o gargalo de cerveja nele; peguei minha bolsa e sai, só que ele tinha tirado o dinheiro da minha bolsa e levou; fiquei nua, nua do jeito que eu nasci. Eu saí da mata eram 8 horas (Zidedê).

\section{VISÕES SOBRE PROSTITUIÇÃO}

A partir dos dados coletados dos trabalhos de campo e das entrevistas, encontramos dois tipos de bares: os que permitem a livre circulação e aqueles que mantêm as mulheres semicativas. Algumas mulheres moram no bar e, nas horas vagas, cuidam da limpeza do lugar. Outras trabalham em um único bar, mas não moram no recinto; e há as que moram em suas casas e frequentam vários bares como free lancers. As mulheres mais velhas, na faixa dos 30 anos, que já estão estabelecidas e até "sindicalizadas", recebem os clientes em casa, de forma autônoma e sem agenciador.

Se pudéssemos classificar nossas entrevistadas, poderíamos agrupá-las em quatro grupos distintos:

- As resolvidas - já estão na trilha da prostituição há anos e não têm problemas com isso. São vinculadas à Associação das Profissionais do Sexo (APROS) e lutam pelos seus direitos, tendo, inclusive, um papel ativo nas suas comunidades.

- As eventuais - têm outras profissões e não se consideram prostitutas; mas, quando é necessário, apelam para esse expediente a fim de completar a renda.

- As temporárias - veem na prostituição a única saída, no geral, após separações e abandono; mas não a assumiram como profissão e nem têm pretensão de permanecer no ofício. - As predestinadas - entram muito cedo na prostituição, têm uma história familiar ou afetiva bastante violenta e sofrida. Parecem não vislumbrar outro destino, nem buscam novos caminhos. Algumas se colocam como fatalistas com relação à atividade, como a que nasceu num bordel do porto de Cabedelo.

Encontramos diferentes tipos de prostituição: desde a vítima de circunstâncias adversas, até as que atingiram a agency, uma minoria, mas existem no interior da Paraíba. Não houve relato de prostituição forçada, apenas induzida ou sugerida por amigas e namorados.

À exceção do primeiro grupo, existe, 
entre elas, a rejeição da prostituição e a incorporação do estigma. O ato de fazer programa aparece revestido de elementos negativos, mas também positivos, sendo um deles a chance de ter mais liberdade.

Que hoje em dia tem o valor, a profissional do sexo, mas é uma coisa que não é [...] não tem aquele valor ainda totalmente, né? É uma coisa que alguém QUER DAR o valor, mas só que não tem. Você chega ali na rua o pessoal "Ó, lá vai a puta, lá vai a rapariga, lá vai isso, lá vai aquilo”, né? Nunca chama "a profissional”, né verdade? Só chama pelo mais feio. Então quer dizer que nunca cai bem com a gente? Você chega num canto, "olhe, aquilo ali” [...] (Sericoia, Mamanguape).

\section{CONSIDERAÇÕES FINAIS}

Todas as narrativas descreveram histórias de vida marcadas pela violência, na família, nos relacionamentos e também com os clientes. Quase todas as mulheres trabalhavam de forma autônoma, mas sob o domínio dos donos dos bares. Contudo, elas construíam estratégias de resistência, como, por exemplo, ao controlar o que era permitido ou não fazer durante as relações sexuais com os clientes. $\mathrm{Na}$ prostituição, ao menos em relação ao próprio corpo, elas adquiriram uma maior autonomia e controle. São elas que determinam o que e como o cliente pode fazer, definem os limites, o preço e as opções. Ao vender os serviços sexuais, elas se apropriam do próprio corpo, empoderamento que não possuem no casamento ou na família.

Com relação à motivação para a entrada na prostituição, tudo gira em torno da família e das relações afetivas. O lugar de cuidado, proteção e amor da família, em muitos casos, se torna negligência, abandono, violência, inúmeros tipos de abuso. Não poucas vezes iniciaram-se na prostituição muito jovens, adolescentes, para fugir dos abusos em casa, na família ou por pessoas próximas, sobretudo os padrastos e vizinhos.
Ao constituírem a própria família, têm filhos cujos pais são ausentes e não contribuem para a manutenção, fazendo com que o sustento da casa recaia sobre elas. Mas os casamentos precoces e o abandono da escola impediram a possibilidade de se profissionalizarem e, assim, encontram poucas oportunidades de trabalho e renda compatíveis com as necessidades de chefe de família. A prostituição é uma oportunidade para mulheres nessa situação.

Nesse sentido, a família é figura-chave na compreensão do fenômeno da prostituição. São pobres e monoparentais. Entretanto, não podemos inferir que a monoparentalidade seja motivadora da entrada na prostituição. Constatamos que inúmeras prostitutas vêm de famílias estruturadas segundo o modelo tradicional, com a autoridade centrada no homem, mesmo quando o pai é ausente e substituído pelo padrasto ou pelo tio, e há uma rígida divisão dos papéis sexuais. Essas famílias reproduzem um modelo no qual as meninas e moças não são valorizadas, como se tivessem nascido no sexo errado.

Raphael e Shapiro (2002) afirmam que a iniciação sexual precoce, antes dos 15 anos, é uma variável significante na população que negocia sexo. Da mesma forma, o abuso infantil, sob a forma de negligência, violência ou incesto, de fato, faz parte da biografia de algumas prostitutas, mas esse dado não permite generalizar ou estabelecer determinações entre a experiência do abuso e a entrada na prostituição (Weitzer, 2007, p. 29).

A relação entre abuso sexual e prostituição não é evidente, mas é sugerida em inúmeros discursos. Algumas foram vítimas de estupro por parente de primeiro grau, padrastos, vizinhos, namorados, sendo a maioria casos de pedofilia. Outras declaram que "se perderam" antes de "ficar mocinha", ter a primeira menstruação. Mesmo quando o estupro gera gravidez, elas ignoram ou recusam a opção pelo aborto legal.

Scott (2001) afirma que o feminismo foi 
o ponto de partida da preocupação com o abuso sexual, surgida nos últimos 20 anos, no discurso médico, legal e no senso comum. Feministas como Rush $(1977,1980)$ e Herman (1981) inauguraram as discussões sobre o abuso sexual no âmbito da família patriarcal, quando o movimento começou a discutir experiências de objetificação e exploração utilizando o estupro como exemplo da subordinação feminina: "O estupro é o ato arquetípico através do qual todos os homens colocam todas as mulheres em estado de pavor" (Brownmiller, 1976). Na ótica feminista, o abuso sexual é uma das peças que compõem a tirania doméstica e interconecta diferentes formas de dominação contra a mulher e as crianças (Griffin, 1981; Kelly, 1988; Stanko, 1985).

As entrevistas demonstram que a violência é recorrente e está presente no ciclo de vida inteira: na família, na vida sexual prematura, nas relações afetivas, na relação com os donos de bares e cafetões, na relação com os clientes, entre as colegas de vida no bar etc. Dessa forma, a violência e o abuso sexual na infância operam como redutores da capacidade de enfrentamento e autoconfiança. E a possibilidade da prostituição surge, em muitos casos, como resposta à violência, ao medo, ao abuso, à falta de poder em situações nas quais elas não 늘 têm controle, como dentro do seio familiar. As j. jovens mulheres que se prostituem nas áreas $\stackrel{8}{4}$ rurais e litorâneas na Paraíba convivem com a 空 exploração sexual há anos e, para tolerar situa\& ções nas quais a experiência da violência masculina e objetificação do corpo fazem parte da $\infty$ experiência cotidiana, constroem mecanismos

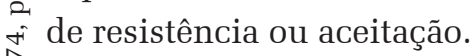


travestem de protetores, mesmo quando usam violência e exploração, e isso permite a interpretação de que há uma associação, nascida na experiência pretérita, entre a proteção, o cuidado e as práticas violentas.

Nosso estudo demonstra, enfim, que não há um gatilho específico que leva a optar pela prostituição; existe uma combinação de fatores que cria condições de risco e situações que desembocam na prostituição (Chesney -lind; Sheldon, 1992). As jovens prostitutas que encontramos no interior da Paraíba são provenientes de famílias rurais, onde as mulheres ocupam uma posição ou um lugar inferior, sujeitas a múltiplas formas de violência, dentre elas a sexual, e que veem na prostituição, ainda na puberdade ou na adolescência, a possibilidade de enfrentamento de suas trajetórias familiares. Do modelo familiar rural para o mundo da prostituição feminina em lugares periféricos, fora dos centros urbanos, elas podem conquistar o direito ao próprio corpo e, ao mesmo tempo, esbarrar em desafios concretos para construir projetos fora desse universo. Por isso, têm expectativas muito baixas quando são interpeladas a pensar sobre sonhos e futuros possíveis. Não querem ser prostitutas para toda a vida; desejam formar uma família, ter um marido e, possivelmente, retornar ao modelo inicial do qual tanto lutaram para sair.

Recebido para publicação em 20 de abril de 2014 Aceito em 19 de agosto de 2014

\section{REFERÊNCIAS}

ALVAREZ, Gabriel; RODRIGUES, Marlene Teixeira. Prostitutas cidadãs: movimentos sociais e políticas de saúde na área de saúde (HIV/Aids). Revista de Ciências Sociais, Fortaleza, v. 32, n. 1/2, p. 53-68, 2001.

BEAUVOIR, Simone de. O segundo sexo. Lisboa: Bertrand, ([1949] 1975).

BROWNMILLER, S. Against our will: men, women and rape. Harmondsworth: Penguin, 1976.

BRASIL. Instituto Brasileiro de Geografia e Estatística (IBGE). Censo Populacional 2010. (29 nov. 2010). Disponível em: <http://censo2010.ibge.gov.br/>. Acesso em: 23 out. 2012

CHESNEY-LIND, M.; SHELDON, R. Girls, delinquency and juvenile justice. Pacific Grove, CA: Brooks/Cole, 1992.

FONSECA, Claudia. A dupla carreira da mulher prostituta. Revista Estudos Feministas, v. 4, n. 1, 1996.

GARCIA, L. NASCIMENTO, S. et al. Família como armadilha. João Pessoa: EDUFPB, 2011.

GRIFFIN, S. Pornography and silence: culture's revenge against nature. London: Women’s Press, 1981. 
HERMAN, J.L. Father-Daughter incest. London: Harvard University Press, 1981.

KELLY, L. Surviving sexual violence. Cambridge: Polity, 1988.

MCMULLEN, R. J. Youth prostitution: a balance of power. Journal of Adolescence, 1987, 10, p. 35-43.

NASCIMENTO, S. Faculdades femininas, saberes rurais - gênero e socialidade em Goiás. Série Publicação Acadêmica Premiada, FFLCH, USP. 2008. http://spap.fflch. usp.br/node/12. Acesso em 30 de junho de 2015.

NASCIMENTO, S. Homem com homem, mulher com mulher: paródias sertanejas no interior de Goiás. Cadernos Pagu, Campinas, n. 39, p. 367-402, jul./dez. 2012.

PARKER, Richard. Bodies, pleasures and passions, sexual culture in contemporary Brazil. Nashville:Vanderbilt University Press, 2009.

PISCITELLI, Adriana. Apresentação: gênero e mercado do sexo. Cadernos Pagu, Campinas, n. 25, jul./dez. p. 7-23, 2005.

Gênero, raça e sexualidade no debate brasileiro sobre tráfico internacional de pessoas In: Segundo Simpósio Diálogos Brasil - EUA - Estudos Antropológicos e a produção da diferença. USP, 16 jun. 2009.

PORTELLA, A. P; SILVA, C. Divisão sexual do trabalho em áreas rurais do Nordeste do Brasil. In: SCOTT, P.; CORDEIRO, R. (Org). Agricultura familiar e gênero: praticas, movimento e políticas publicas. Ed. UFPE: Recife, 2006.

RAPHAEL, J.; SHAPIRO, D. Sisters speak out: the lives and needs of prostituted women in Chicago. A research study. Chicago: Center for Impact Research, 2002.
RUSH, F. The freudian cover-up. Chrysalis, n. 1, p. 31-45, 1977. 1980.

The best kept secret. New York: Prentice Hall,

SCOTT, Sara. Surviving selves: feminism and contemporary discourses of child sexual abuse. Feminist Theory. 2: 349, 2001.

. The politics and experience of ritual abuse: Beyond Disbelief. Buckingham: Open University Press, 2001.

SIMMEL, Georg. As grandes cidades e a vida do espírito (1903). Revista Mana. Rio de Janeiro, v. 11, n. 2, 2005. . Philosophie de l'argent. Paris: PUF, 1988.

STANKO, E. Intimate Intrusions: Women's Experience of Male Violence. London: Routledge and Kegan Paul, 1985.

STOLCKE, V. Gênero mundo novo: interseções A Formação dos Impérios Transatlânticos do Século XVI ao XIX. In: Reunião Brasileira de Antropologia ( $2^{\mathrm{a}}$ Goiânia: 2006) Conferências e práticas antropológicas. Blumenau: Nova Letra, 2007.

TEIXEIRA RODRIGUES. Prostituição e polícia: um estudo de caso. Tese de Doutorado em Sociologia - Departamento de Sociologia, Universidade de Brasília, 2001.

WEITZER, R. Prostitution, facts and fictions. Contexts, n.4, p. 28-33, 2007.

WEST, J. Prostitution: collectives and politics of regulation. Gender, Work and Organization 7 (2), 2000. 
IN THE TRAPS OF DESIRE: deprivation and movements of young prostitutes in rural areas

\section{Silvana de Souza Nascimento Loreley Gomes Garcia}

The objective of this article is to discuss the ambivalent meanings from the locus of female prostitution from a study conducted with young women in the countryside of the State of Paraíba (North Coast and swamp regions), from rural families. The life histories of these women reveal a family history characterized by various types of violence and different autonomy strategies in order to overcome these experiences of deprivation, although they often recur in their relation with the pimps and customers. Prostitution is seen as a strategy of empowerment regarding their own body, the mastery over unconventional sexual practices and, at the same time, as a temporary situation, seen as a means to build future projects, at least ideally, outside of prostitution. Our socioanthropological study reveals that the mechanisms for the acquisition of autonomy reproduce a model of domination and offer few opportunities for these young people to resist current norms and morals.

KEYwORDs: Female prostitution. Youth, rural environment. Paraíba. Family.
DANS LES PIÈGES DU DÉSIR: privations et mouvements de jeunes prostituées en zones rurales

\author{
Silvana de Souza Nascimento \\ Loreley Gomes Garcia
}

Cet article se veut de poser le problème de l'ambivalence des sens donnés à la place de la prostitution féminine. Il est fondé sur des enquêtes effectuées auprès de jeunes femmes issues du milieu rural dans la campagne de l'état de Paraiba (région du Littoral Nord et de la région marécageuse). Les trajectoires de vie de ces femmes révèlent un historique familial marqué par divers types de violences et par différentes stratégies d'autonomie pour surmonter ces expériences de privations, même si, très souvent, celles-ci se répètent dans leur relation avec des proxénètes et des clients. La prostitution est considérée comme une stratégie d'appropriation de son propre corps, de pratiques sexuelles peu conventionnelles et, en même temps, comme une situation transitoire perçue comme un moyen de construire des projets d'avenir, pour le moins dans l'idéal, hors prostitution. Notre recherche, de par son caractère socio-anthropologique, révèle que les mécanismes d'acquisition de l'autonomie reproduisent un modèle de domination et offrent peu d'alternatives permettant à ces jeunes de résister aux normativités et aux moralités en vigueur.

Mos-Clés: Prostitution féminine. Jeunesse. Zone rurale. Paraíba. Famille.

Silvana de Souza Nascimento - Doutora em Antropologia Social. Professora do departamento de Antropologia da Universidade de São Paulo. Pesquisadora do Laboratório do Núcleo de Antropologia Urbana (LabNAU) da USP. Foi docente da Universidade Federal da Paraíba de 2007 a 2012 e, durante esse período, realizou pesquisas sobre prostituição, transexualidades e as relações entre campo e cidade. Atua como professora colaboradora no Núcleo de Cidadania e Direitos Humanos da UFPB e como pesquisadora do Grupo de Pesquisa em Etnografias Urbanas (Guetu), da UFPB. Faz parte do corpo editorial da coleção Sexta Feira - Antropologia, Artes e Humanidades. Publicações recentes: Corpo aberto, rua sem saída. Cartografia da pegação em João Pessoa. Sexualidad, Salud y Sociedad (Rio de Janeiro), p. 44-66, 2015; Family as a trap: the other side of family agriculture. International Journal of Humanities and Social Science, v. 4, p. 84-94, 2014; Variações do feminino: circuitos do universo trans na Paraíba. Revista de Antropologia (USP. Impresso), v. 57, p. 376-411, 2014; Corpo-Afeto, Corpo-Violência: Experiências na Prostituição de Estrada na Paraíba. Revista Ártemis, v. 18, p. 69-86, 2014.

Loreley Gomes Garcia - Doutora em Sociologia. Professora da Universidade Federal da Paraíba, onde atua nos Programas de Pós-Graduação em Sociologia e no Programa de Meio Ambiente e Desenvolvimento. Foi Professora Visitante na Temple University (2010) e bolsista da Fulbright Foundation. Realizou estudos, estágios e pesquisas na Universidade da California - Berkeley (2001/02), Southern Oregon University (2010), Hamburg Universität (1987/89). Áreas de atuação: Cultura e Natureza, Éticas do Ambiente, Anarcoecologismo, Estudos de Gênero e Sexualidades, Feminismo e Juventude, Gênero e Desenvolvimento, Prostituição juvenil, Mulheres rurais e indígenas, Deslocamentos e Globalização. Publicações recentes: Family as a trap: the other side of family agriculture. International Journal of Humanities and Social Science, v. 4, p. 84-94, 2014; Family girls: a study about juvenile prostitution in the indigenous areas in Northeast of Brazil. International Journal of Gender and Women's Studies, v. 2, p. 1-25, 2014; Família como armadilha: o outro lado da agricultura familiar. Política \& Trabalho (UFPB. Impresso), v. 38, p. 251-269, 2013. 